a brief account of Frazer's work. Regarding the condition of œsophago-tracheal fistula the theory that it is due to malformation of the cesophago-tracheal septum is still put forward in spite of the inadequacy of the explanation.

At the end of each chapter under "Notes" are references to important recent papers bearing on the subject matter; these are most valuable. The illustrations are numerous and are very clear and well annotated-a fact which is appreciated by students of embryology. The book has a distinct clinical flavour, the author having written "for men who are to be practical physicians and surgeons". The book is valuable to the busy doctor who strives to keep an academic interest in his work and to the student who seeks a sound practical knowledge of Embryology which will help him in his clinical studies.

We commend this book and note that it comes to us from the Buckston Browne Research Farm.

\section{A SYSTEM OF CLINICAL MEDICINE.}

Thomas Dixon Savill, M.D. (London). (9th Edition). Edward Arnold. Price 28/-.

Savill's System of Clinical Medicine has reached its 9th edition - a noteworthy achievement-and the present publication is edited by Dr. Agnes Savill, assisted by Dr. E. C. Warner. The work describes diagnosis, prognosis and treatment, particular emphasis being paid to differential diagnosis.

When the late Dr. Thomas Savill wrote his System, diagnosis was based largely upon clinical experience, and present-day students of medicine, both under-graduate and post-graduate, will profit greatly from a careful study of those clinical methods of diagnosis so fully described in this book. As later editions proved the need of such a book, so laboratory and other aids to diagnosis have become more important and useful and the present edition contains a full account of these methods. Thus, one of the chief recommendations of this work is a happy combination of clinical and laboratory methods in diagnosis. The sections on treatment are brief but concise and very helpful. Dr. Agnes Savill in the present edition has been fortunate in obtaining the collaboration of a number of authorities including Drs. Maurice Davidson, Hamilton Fairley, Strickland Goodall and Redvers Ironside. Together, they have produced a book full of the most practical information and we strongly recommend it to our readers.

\section{AN INTRODUCTION TO THE STUDY OF THE NERVOUS SYSTEM.}

E. E. Hewer and G. M. Sandes.

London: Heinemann $1933 . \quad$ Price 21/-.

The Post-graduate student wishing to devote some time to neurology-whether or not for the purpose of examinations-is usually exercised in the choice of a suitable guide to the anatomy and physiology of the nervous system. It may be stated at once that no one book to-day can be recommended as adequate in presenting a modern and concise account of nervous structure and function, possessing at the same time a clinical bias. In the circumstances the student has to do his best with such books as are available. The recent 2 nd edition of Hewer and Sandes' "Introduction to the Study of the Nervous System" will impress itself favourably. The reading matter is terse and to the point; the diagrams excellent in their clarity and simplicity-illustrating incidentally the invasion of New Art conceptions into the realm of medicine! Obviously it is not impossible to criticize some of the views expressed on such a rapidly evolving subject as neurology. Here and there we find statements of theory and opinion which have been solemnly passed on from book to book until they have formed almost a tradition. Many of such view points have become a little threadbare with time. So long however as examiners, browsing on memories of the Past, continue to expect the regulation "penny in the slot" answer to the traditional question, students will be compelled to demand traditional doctrine in their text books. As things stand to-day the student cannot do better than choose Hewer and Sandes' "Introduction," and if he can absorb all that the authors present, he will go a very long way towards an understanding of neurological anatomy. 